\title{
Long-term care and intermediary structures for frail older people: Switzerland and Germany in comparison
}

\author{
Konstantin Kehl, kehl@zhaw.ch \\ Zurich University of Applied Sciences, Switzerland \\ Rahel Strohmeier Navarro Smith, strr@zhaw.ch \\ Zurich University of Applied Sciences, Switzerland
}

Long-term care not only includes residential care, home care and familial care, but services 'inbetween', such as day and night care, temporary (short-term) stays in nursing homes, respite care, and local infrastructure giving informed advice and conveying informal support. In both Switzerland and Germany, the role of such intermediary structures has been debated and affected by social policy reforms. The authors analyse different functions of intermediary structures, discuss their access and use, and show that intermediary structures can have a different impact on care regimes.

key words

long-term care - intermediary structures - day and night care - social innovation - path dependency

\section{Introduction}

Ageing populations and the effects of demographic development on care needs will be fundamental challenges in coming years. Western democracies and social policymakers will have to answer the question of how they ensure support and high-quality care for older people in times of societal modernisation and public budget constraints. At first sight, the welfare systems of Switzerland and Germany are both comparatively well prepared to cope with demographic challenges. In Switzerland, long-term care (LTC) is part of the health insurance system and social policy reforms have recently adjusted the financing of care and introduced additional services to supplement residential, home and familial (informal) care. Specialised LTC insurance (LTCI) does not exist, and the focus in the past 20 years has been on promoting publicly financed home-care services (Strohmeier Navarro Smith, 2012). In Germany, the Christian and Social Democrat government established a LTCI scheme in 1995, 
funded - in the Bismarckian tradition - equally by employers and employees. A central aim is to encourage outpatient (home-based) and informal care rather than inpatient (residential) services, using cash-for-care benefits. German policymakers also established services to complement residential care, home care and informal (family) care.

In both countries, 'in-between' services are a matter of discussion. These are social and health care services for frail older people provided by professional staff that support caring relatives (carers) and enhance the quality of care. Specifically, they involve 'day and night' care, temporary (short-term) stays in nursing homes, respite care, and local infrastructure services providing information, advice and other informal support. We use the term 'intermediary structures' as these services are neither strictly institutionalised (in the sense of inpatient care) nor located in the private homes of people in need, where professional outpatient services and informal (family-based) contributions to care are usually found (Werner et al, 2016). ${ }^{1}$ Intermediary structures refer to paid-for services (irrespective of who pays) and not to informal (familial) care. Intermediary structures are thought to have positive effects on carers (informal caregivers $^{2}$ ) as they reduce the pressures of care by providing opportunities for respite and expert advice, and facilitate low-level assistance with everyday activities. In so doing, they strengthen the societal capacity for informal care and serve as a buffer against rising costs caused by the greater use of professional care.

Growing numbers of people in need of care and assistance in old age - a trend accompanied by a fall in family caring because of changed family structures, labour mobility and increasing female employment - will lead to additional costs if the preferred answer is to simply 'scale up' conventional inpatient and outpatient care arrangements. Experts in both countries are therefore debating the role of intermediary structures, and recent social policy reforms have encouraged their dissemination: on the one hand, they may enable frail older people to remain at home for longer, before moving to a nursing home; on the other hand, they are designed to better prepare people to accept responsibility for the care of a loved one at home or to come to terms with (costly and therefore often limited) outpatient care provided by professionals. Taking Switzerland and Germany as examples, however, intermediate structures seem to serve different functions and to have different effects on formal and informal care arrangements in different institutional frameworks.

We aim to reveal the differences in two countries with a 'conservative' welfare tradition - Switzerland and Germany - in which families have so far played a crucial role in the provision of LTC. ${ }^{3}$ In comparing the two countries in the context of their welfare architecture and institutions, the article discusses three research questions:

- How should intermediary structures be located in current LTC models, that is, which functions within the specific institutional frameworks and care arrangements do they serve?

- Can we identify differences regarding access and use?

- Is the introduction of new forms of LTC services compatible with the welfare tradition and conventional care arrangements, that is, in what sense can their introduction be seen as path-dependent, or can it be interpreted as a 'social innovation'? 
We analyse the different concepts of intermediary structures, compare findings regarding access and use in the Swiss and German cases, and draw conclusions with regard to their fine-tuning potential in the (care-related) welfare mix. The third to fifth sections of the article deal with the three main research questions. Despite starting from similar welfare conditions, we show that intermediary structures have been set up in a different way, and tend to have different effects on care regimes: in Switzerland, intermediary structures serve as a kind of 'gateway' into the professional system; whereas in Germany, they are designed to support informal (familial) care. Although the article does not offer a full policy analysis, it provides fruitful explanations regarding institutional, socio-economic and cultural factors, and tells a rather different story in two countries commonly associated with the 'conservative' welfare regime.

\section{Intermediary structures between path dependency and social innovation}

This section outlines the social policy discourse and welfare regime conditions in the two countries and care systems. It lays the foundation for our analysis of intermediary structures and allows us to formulate assumptions about our research questions. On this basis, we later explore the functions of intermediary structures in the two specific institutional frameworks, analyse differences regarding access and use, and discuss the question of whether intermediary structures are consistent with their welfare tradition and with extant care arrangements. If not, we can speak of a 'social innovation', in the sense that these are new services, products or processes intended to solve (new) social problems or to cope with social risks as a reaction to social needs (Krlev et al, 2014).

The institutional function, the modes of policymaking and their embeddedness in public discourses and welfare regimes are central to the analysis, not least because federalism is more pronounced in Switzerland and the strong direct democratic procedures there make it challenging to change the status quo (Knöpfel, 2015). Second, this may give rise to an expectation of more universal access and use of intermediary structures in the German case, where LTC issues are subject to national policies in a representative democratic system with two powerful welfareoriented parties (at the national level). Third, and in combination with established routines of service delivery and demand, there may be 'feedback loops' between care arrangements and welfare regime principles. One could argue that more universal access to intermediary care contributes to the reconciliation of work and family life, and therefore to a shift from familial to professional care services. Conversely, one could argue that care is not without cost, and that in a system that only partly covers the costs of care, up to a certain maximum, people will decide to provide care themselves (instead of paying for professional services). In this case, intermediary structures would have the opposite effect and would tend to support traditional informal (familial) care arrangements.

Intermediary structures have to be interpreted within the country-specific welfare traditions of the countries studied. In Esping-Andersen's (1990, 2002) landmark typology of welfare regimes, the German welfare system is considered a pioneer country with a strong focus on social insurance systems and families, whereas the Swiss case represents a latecomer, which only 'caught up' in the 1990s (Obinger and Wagschal, 2000). Today, both countries can broadly be assigned to the 'conservative' 
regime, which is characterised by social policies conceived in a meritocratic way, with strong social insurance principles, whose aim is to maintain family care. Despite policy change in terms of programmes supporting the reconciliation of work and family life and appreciating the value of household work, families are the prevailing social agency, and are therefore strongly supported in their caring role in these welfare environments (Kazepov, 2010).

Old-age dependency can still be seen as less decommodified compared with other social risks, such as accidents, sickness or unemployment, which were addressed earlier in the history of the welfare state (Bonoli, 2005; Strohmeier Navarro Smith, 2012). In the provision of LTC for frail older people, families have always been of great importance and still play a crucial role in Western industrialised societies. Public service provision is expected to be subsidiary to familial care, especially in the case of the 'conservative' welfare regime (Strohmeier Navarro Smith, 2010). Pluralism among LTC policies, with new forms of cooperation arising between different societal sectors, has become the often-stated explicit goal of recent LTC policies, containing new and old expectations towards family care (Ungerson and Yeandle, 2007; Pfau-Effinger, 2008a; Saraceno, 2008). This invites scrutiny of whether introducing intermediary structures enhances conventional schemes or shifts care responsibilities (Saraceno, 2008; Strohmeier Navarro Smith, 2010). We could even ask if they contribute to 'locking in' traditional care arrangements, resulting in a (re-)familisation of care. In looking at the functions of intermediary structures within institutional frameworks and care arrangements, we have to admit that the more autonomous sub-national levels are in defining LTC provision, and the less coercive national laws are, the more probable it is that regional variation will occur in the delivery of LTC. This is particularly the case in Switzerland, but much less in Germany. Consequently, access can generally be jeopardised by both the (re-)familisation and regional variation of LTC delivery (Strohmeier Navarro Smith, 2010).

Discussion of social investment strategies in public policy can shed light on our investigation of innovations, that is, new services, products or processes in LTC. Social investment paves the way for a new balance between 'social-democratic' redistribution and a 'liberal' focus on individual responsibility, based on markets and 'conservative' familism (Esping-Andersen, 2002; Hemereijck, 2013). It aims to empower people through a life-course perspective (Giddens, 1994) via prevention and investment in education and work-life balance approaches. Such strategies seek to prevent societal problems from arising in the first place through a combination of redistribution and social insurance programmes and the encouragement of individual self-help, self-organisation and the co-production of welfare. In care, this approach not only refers to the capacity of families, but also to informal and civic networks outside the household. Intermediary structures can be seen as a way of promoting such resources and adjusting 'conservative' familism as they are intended to strengthen the infrastructural foundations for LTC in times of changed family relations, perceptions of responsibility and labour regimes. They are in line with social investment thinking since their political aim is to 'allow individuals and families to maintain responsibility for their wellbeing via market incomes and intra-family exchanges, as well as lessen the threats to welfare regimes and their programmes coming from ageing societies and family transformations' (Jenson, 2012: 61f.). Proponents of the social investment state assign the state a key role in moderating, facilitating and safeguarding mixed welfare arrangements - not in welfare provision per se - even though not all policy 
environments are well equipped for investment approaches (Kazepov and Ranci, 2017).

Taken together, we begin with the classic welfare regime typology and assign the Swiss and German cases to the 'conservative' regime, with a strong focus on social insurance systems and familial care. In such regimes, old-age care is less decommodified compared with more 'traditional' social risks and is generally seen as a family responsibility. Specific modes of policymaking and their embeddedness in the welfare regime - such as the federal fragmentation of competencies and democratic routines of decision-making - may affect how LTC provision is defined, probably with more regional variation in the delivery of LTC where national laws are less prescriptive. We can nevertheless identify a trend towards promoting innovations in social services and a new balance of responsibilities. Given that debate, we can assume that intermediary structures are key to opening up traditional care arrangements and adapting the state's role in favour of a more moderating, facilitating and safeguarding function in the overall provision of LTC.

\section{The role of intermediary structures in the LTC models of Switzerland and Germany}

In this section, we start with the first of our three questions outlined in the introduction. We seek to analyse the role of intermediary structures in the current LTC models of the two countries. We take a closer look at the discourses and policy environment through which they came on to the agenda and were introduced as new concepts for dealing with challenges in old-age care, then contrast their characteristics in more detail, and finally investigate which functions they serve within specific institutional frameworks and care arrangements.

\section{Intermediary structures as new approaches to care in LTC discourse}

In Switzerland, intermediary structures are the product of a more recent debate. Even in the wealthy Swiss confederation, with its now generous system of welfare, public discussion on the financial sustainability and demand orientation of existing service provision is under way. Recently, publicly funded research projects (Bischofberger et al, 2014; Köppel, 2015; Werner et al, 2016) have addressed specific and new forms of LTC beyond professional (residential and home) care and familial care. These were mostly developed at parliamentary request and were summarised in a Federal Council policy report (Bundesrat, 2014), which presents intermediary structures as a triple-win solution for caring relatives (reduction of their care burden), frail older people (staying at home for longer) and the welfare state (postponed entries to nursing homes). Intermediary structures are thus seen as one piece (among others) in improving conditions for informal care (such as regulating short-term absences from paid work, introducing care leave or monetary benefits for informal care).

However, since national LTC law implementation is subject to legislation at the 'canton' and municipal levels, with different structures of welfare governance and delivery (eg more market-oriented mechanisms in the German-speaking part and rather statist approaches in the French-speaking regions), there is no comprehensive and homogeneous intermediary structure landscape. On the contrary, they are more common and widespread in regions with high user rates for residential and home-care 
services (Werner et al, 2016). As a vehicle to address the 'blind spots' of the existing LTC architecture - and mostly run by established service providers to make greater use of their capacities (with available staff) - we can take this as an argument for path-dependent developments, which also applies for other LTC services (Strohmeier Navarro Smith, 2012).

A newer argument refers to the potential for reconciling family duties and paid work (Bundesrat, 2014): more than half of all women and men in Switzerland have to deal with the care needs of their relatives in midlife (between age 50 and 64).

Among carers, $17.5 \%$ say that they would organise their working life differently if care for their relatives was better organised. Insofar as working conditions are not flexible enough, or in cases of high care needs for extended periods, relatives often have to choose between informal care or continuing to work, or - if possible - reduce their workload. If they decide against employment, they risk lower income and can face gaps in personal social protection linked to their labour market activity. Furthermore, households with two adults increasingly depend on two incomes (Bundesrat, 2014). The question thus arises of whether intermediary structures support a more balanced division of informal care - or even if they strengthen the current care regime. As an initial critique, it can be noted that the Federal Council's report did not discuss crucial topics such as the division of care tasks between (working) men and women, even though other studies have shown that gender regimes strongly influence the provision of unpaid, informal, familial care (Razavi, 2007). Two thirds of informal care in Switzerland is provided by women and one third by men (Perrig-Chiello et al, 2010). An interesting question is whether intermediary structures affect the gender division of care obligations.

In Germany, the issues are slightly different. When LTCI was established in the mid-1990s, a central aim was to prioritise outpatient and informal care over professional (inpatient) services in nursing homes. Since then, people in need of care (as determined by a medical review board) can choose between in-kind benefits and cash-for-care payments (or a combination of both); the latter tend to encourage family and non-family care in the home environment. LTCI payments are capped and cover about half of total costs for care and maintenance/general expenses (the latter have to be covered privately or through municipal social welfare). ${ }^{4}$ Intermediary structures were introduced to support carers by giving them legal entitlements to respite care, day and night care, and short-term stays in nursing homes. The most important instrument in deinstitutionalising care is, however, lump-sum cash benefits. The rationale behind these 'is based on the idea that the state (public authorities) contributes a certain amount of resources to the costs of care, and it implies an individual and family responsibility for covering any other costs' (Da Roit and Le Bihan, 2010: 298). In fact, the system produces strong incentives to informal care: while capped payments for professional care cover only part of its cost, cash benefits often serve as additional family income. From a household-economic perspective, this leads to a situation in which the family members with the lowest (possible) income and labour market opportunity costs - traditionally women - bear the burden of care (Schneider, 2006).

As a result of educational expansion in Germany in the 1960s and 1970s, women have much better employment opportunities today than their mothers or grandmothers did, and are less willing to function as the 'natural resource' of care. This trend has been accompanied by considerable change in family structures arising from 
fewer children (or childlessness) and more short-term relationships instead of formal marriage, further reducing the familial reservoir of potential carers. Consequently, cash-for-care arrangements continuously lost ground over the past two decades, and it will be a major challenge to sustain the level of informal care in the existing LTC structure (Kehl, 2016a). This makes the political goal of strengthening informal care almost unachievable. Approaches designed to mobilise complementary resources for care and support, and new alliances between different actors in neighbourhoods and wider communities (service providers, real estate management, local administrations, etc), have been discussed (Heinze, 2017). The dissemination of such approaches would contribute not only to reduced costs, but also to a better quality of life and the greater public legitimacy of LTC policies, since people in need of care prefer to stay at home for as long as possible (Kehl, 2016a, 2016b). Intermediary structures, such as local support centres for carers and new forms of community-based living providing assistance in case of need, as well as care leave opportunities, are part of these new policies. They respond to the insight that monetary incentives to encourage informal care are limited by cost-utility considerations and intrinsic motivations (Kehl and Stahlschmidt, 2016).

\section{Characteristics of intermediary structures in Switzerland and Germany}

In the Swiss LTC system, intermediary structures are found primarily in so-called 'day and night care' structures (Tages- und Nachtstrukturen), in special (and partly publicly subsidised) apartments for older people with care services (Werner et al, 2016) and respite services for family carers, usually in their own homes (Bischofberger et al, 2014).

Day and night care structures provide support to family carers by enabling them to retreat from caring obligations for a limited time. Specialised staff (eg qualified nurses) guarantee care and support to older people with care needs and mentally disabled people. There are about 400 such facilities in Switzerland, of which two thirds are in residential foster-care homes. Uptake of these services is limited, however: there are approximately 330,000 carers in Switzerland, but only 4,300 people use the services of day and night care structures per year. Yet, they are using them on a very regular basis (three times a week), despite - or perhaps because of - the fact that care recipients using day and night services have rather low needs compared with the average care recipient (Köppel, 2015; Werner et al, 2016).

The reasons for low usage rates can be found in variations in fees, as well as in the 'image' of day and night care structures. Although health insurance covers most healthrelated

costs for day and night care arrangements, prices vary for users, from 40 to 140 francs per day, and 50 to 215 francs per night. This can create doubts about the quality of care and effective cost-benefit ratios, and is simply not affordable for some people. Other problems are a lack of information, emotional factors and perceptions: surveys show that people dislike the 'nursing home smell' of some the services, and carers feel uncomfortable sending relatives to third-party institutions (Werner et al, 2016). For many, caring is psychologically and physiologically demanding but, at the same time, felt to be enriching for the carer (Walker et al, 1995; Roth et al, 2009). In Germany, there is a comparable day and night care system (Tages- und Nachtpflege). In contrast to Switzerland, it is part of the LTCI scheme introduced in the 1990s. People in need of care who receive care from a family member or neighbour in their 
home environment are legally entitled to use such services and may spend $50 \%$ of their LTCI benefits on day and night care. They can also use short-term and respite care in a nursing home (eg during holidays) for up to four weeks per year. In both cases, LTCI covers the costs of care but not those of meals and accommodation (BMG, 2017), a mechanism that prevents more widespread use of day and night care facilities. Apartments with services are also available in Germany.

A network of several hundred local support and reception centres - so-called 'care bases' (Pflegestützpunkte) and 'social stations' (Sozialstationen) - has also been built up over the past decade, triggered by national legislation in 2008. These centres - partly run by non-profit service providers, partly by municipalities and partly as joint ventures - do case management, allow carers to obtain informed advice and find low-level neighbourhood support to complement their own care, or provide professional services. They were intended to be a focal point for carers and to connect different forms of support in a welfare mix. Despite early ambitions, the idea of local centres did not become one of the sustaining innovations of care policy, as we will see later. However, in combination with the LTCI coverage and the right to take care leave (without earnings replacement), they have an important role in the care architecture. In addition, there are model federal government and state programmes to develop shared apartments and support for community-based living (Kehl, 2016b).

\section{The function of intermediary structures in the Swiss and German LTC systems}

In both countries, a 'blurring of boundaries' between formal and informal care has been observed (Pfau-Effinger, 2008a, Saraceno, 2008; Strohmeier Navarro Smith, 2010). This implies that both professional staff and non-professionals can, and are expected to, be involved in providing LTC for frail older persons. Intermediary structures enhance this new mix of formal and informal care but cannot cover all care needs throughout the 'care biography'. When care needs are high, older people still need to enter a nursing home (Strohmeier Navarro Smith, 2010). At the start of the care cycle, when only low needs have to be met, relatives tend to 'jump in' as access to publicly funded services is limited (Strohmeier Navarro Smith, 2010). Thus, intermediary structures are merely an addition to existing arrangements between inpatient care (provided by professional staff) and outpatient care (provided by a mix of professionals, relatives and neighbours) - not least because both the Swiss and German structures require extra private payments that people tend to circumvent if they are able to care informally.

In the landscape and characteristics of intermediary structures in Switzerland and Germany (see Table 1), there are both similarities and differences in whether care is provided formally or informally, the level of care need addressed, and their organisation, governance and financing. The main differences between intermediary structures in Switzerland and Germany concern governance and financing. In Switzerland, despite the regulation of health insurance and national legislation on the financing of LTC services, LTC models are still mainly defined at the cantonal and municipal levels (Strohmeier Navarro Smith, 2012), whereas the German system is more homogeneous and intermediary structures are part of the national care insurance 'toolbox'. Regarding care needs, both models cover the range from inpatient (residential) to outpatient (home and community) services, whereas it is only in Germany that building infrastructures for informal assistance (such as local 
support centres) are part of a nationwide policy, in line with a more informal approach. Not only are there cash-for-care payments that favour family care, but intermediary structures also aim to supplement the low-level support provided by local community networks. In Switzerland - as we will see later in more detail - LTC focuses more on professional resources.

As a preliminary finding concerning how intermediary structures function, we argue that in Switzerland, they are seen as just one piece in a bigger jigsaw of approaches to better support families and relatives. Political discussion and programmes emerged only a few years ago, and essential social and economic issues, such as the division of care between men and women, have been touched on only marginally. The dominant theme is the stabilisation of a successful model, in which (comparatively well-paid) professionals ${ }^{5}$ and family members provide high-quality care in a cooperative partnership. This is supported by relative economic wealth (see later) and an institutional system in which sub-national cantonal and municipal powers and decision-making authorities result in a fragmented landscape of discourses and policies. The more centralised institutional framework and policy system in Germany, accompanied by considerable problems with the current LTC system and a lively discussion about shortages of nursing staff, leads to a different situation. Here, intermediary structures are considered to be breaking new ground by mobilising necessary complements to (or substitutes for) traditional (family) resources. In this way, they may also stabilise existing care regimes or encourage care immigration. Even with cash-for-care benefits, which encourage household care, there are still strong incentives for care arrangements in the family context (or outsourcing care to low-wage earners) that are supported by a (better) care infrastructure.

\section{Access and use of intermediary structures}

In the following, we analyse differences regarding access to, and use of, intermediary structures in Switzerland and Germany (see Table 2). Due to a lack of comparable data on the full range of intermediary structures, our focus is on day and night care services, which are found in both countries. 'Access' is operationalised by examining whether or not there is a legal entitlement to these services, the eligibility criteria for accessing publicly financed day and night care services, and which costs people have to co-finance (higher extra payments being a more restrictive factor). In contrast, 'use' is a more straightforward indicator referring to output data, such as the number of daily visits (Switzerland) or the share of day and night care services in total LTCI usage 
days (Germany). These differences in measures arise from the different organisational and financing structures, as previously mentioned.

In Switzerland, there is no national legislation clearly defining access to day or night care structures. In theory, anyone can use them, although access is, in fact, restricted by financial and cultural factors. Concerning the financial aspects, national legislation on compulsory health insurance financed by premiums, introduced in 1996, plays a crucial role. This regulates health-related care costs for health care services prescribed by a physician. Further, more recent national regulation of health care financing, from 2011, states that health care beneficiaries should pay up to a maximum of $20 \%$ of health-related care costs, plus a 10\% general user payment (plus a franchise up of to CHF2,500 per year). Cantons or municipalities have to pay for other health-related costs not covered by health insurance. Non-medical care services are means-tested, so only beneficiaries with incomes below the (nationally regulated) poverty line get support. In practice, differentiating between health-related and non-medical care services is very difficult.

Within the framework, people do not need a specific level of care need to use the day and night structures, although a health assessment is needed to cover health-related care costs using public health insurance. Additional costs for support and assistance must be paid for personally. The cantons and municipalities retain a strong say in whether or not they provide further financial incentives to enable older people to remain at home as long as possible, moving to a nursing home only when familial and professional outpatient care services have reached their limit. Day and night structures offer a further option in public care arrangements to prevent extended stays in nursing homes or hospitals and to support informal home care. However, recent research shows that many carers are reluctant to use such day and night structures, or simply do not realise or accept their own need for support. Other reasons for their low use include high costs, a lack of targeting towards specific groups and poor accessibility for, and insufficient attention to the needs of, caring relatives (Bischofberger et al, 2014). In general, regional variation between the cantons in the provision of day and night care is high: in the French-speaking part, there are 17.1 places for day care per thousand inhabitants aged 80 and older in the canton of Vaud, as compared with no offer of such services in the German-speaking canton of Glarus, and only 2.4 places for day care per thousand inhabitants aged $80+$ in the canton of St. Gallen at the German border (Werner et al, 2016). Just $9 \%$ of these structures are run by the public sector (municipalities), apart from three cantons where day and night care structures are publicly funded (Werner et al, 2016). 
There is also high regional variation in the use of day and night care structures. In the French-speaking part of Switzerland, there are 27 beneficiaries per thousand inhabitants aged 80+ in the canton of Fribourg, whereas in the German-speaking part, for example, in the canton of Glarus, there are regions with no such public services at all. In the canton of Obwalden, there are eight beneficiaries per thousand inhabitants over 80 (Werner et al, 2016). A similar pattern applies to daily visits: in the French-speaking part, there are 6,000 visits per thousand inhabitants over 80 in the canton of Vaud, whereas in the German-speaking part, there are only 3,000 visits per thousand inhabitants over 80 in the canton of Basel-Stadt (Werner et al, 2016). As already mentioned, user rates for day and night care structures in Switzerland are generally rather low, and the reasons for this low or non-use is presently being investigated in a research project funded by the Federal Office of Public Health. ${ }^{6}$ In contrast to Switzerland, in Germany, intermediary structures are more regulated at the national level, through the LTCI scheme (although implementation may be delegated to states and municipalities, which must guarantee a certain level of social services). Day and night care structures are part of the nationwide legal framework and embedded into a regulated quasi-market dominated by major for-profit and notforprofit service providers. Due to considerable investment in inpatient (residential) care and retirement homes after the LTCI scheme was established, and a now average utilisation of below $90 \%$, there are incentives for organisations to fill their vacancies by providing flexible, temporary services. The 'care bases', initiated by the federal government in 2008, did not become a sustainable care policy innovation because their scope was seriously reduced during the policy formulation process. Their use highly depends on state and municipal legislation. Like their counterparts - 'social stations' - they are nevertheless important in case management and consultancy, which some approved care recipients and their relatives are legally entitled to use. As already mentioned, German LTCI usage rates have changed over the past two decades, especially with respect to cash-for-care benefits, which have lost ground. The core of intermediary structures - day and night care structures - have to cope with growing demand. Between 1997 and 2016, the share of day and night care services in total LTCI usage days increased from $0.3 \%$ to $2.8 \%$, the share of respite/ short-term care increased from $0.3 \%$ to $0.8 \%$, and the share of special 'vacation care' (Urlaubspflege) increased from $0.2 \%$ to $4.5 \%$. The increase arises because fewer carers feel able to care (alone) 24/7 (and, instead, need assistance more often) and because care arrangements increasingly involve more people - for example, non-family members or men - who contribute only small amounts of time (Kehl, 2016a). The availability of services as a legal right, and relative financial certainty through social insurance benefits, has helped build a stable market and increase the use of services. In contrast to Switzerland, regional variation in Germany is rather low and can, at best, be explained by general differences between the states; the highest care needs are in the East-German and more rural states of Mecklenburg-Vorpommern and Brandenburg (51\% of the cohort aged 85 to 89), as compared with a much lower rate (34\%) in wealthy Bavaria (Statistisches Bundesamt, 2017). This can be traced back to the national LTC legislation and quasi-market, but regional variation is also evident where there is no such umbrella framework. Regarding the 'care base' infrastructure, in the process of policy formulation, decisions about its implementation were delegated from the national to the state level. Contrary to expectations, only a few have been established (some states have prevented their introduction) and usage rates are rather 
low (Kehl, 2016b). Nevertheless, intermediary structures serve a useful function, not least because institutional care in Germany seems to be moving towards care for the oldest, hospices and 'high-class' retirement homes, whereas different forms of living independently at home - supported by intermediary services, for example are increasing, in line with the wishes and demands of older people (Kehl, 2016b; Heinze, 2017).

In sum, intermediary structures exist in both countries, but access to them is determined by legislation, producing different usage effects. In the example of day and night care structures, we have shown that the Swiss case is characterised by regional variation because of weaker national law - entailing differences in access and use whereas in Germany, where they are part of the universal LTCI scheme, their usage has generally increased. The sparse available data need to be further investigated, however, to take into account, for instance, long-term developments in user rates for residential and home care, and their interaction effects with intermediary services.

\section{Intermediary structures as evidence for path dependency or social innovation in LTC policy?}

In this section, we examine if the introduction of intermediary structures is consistent with the welfare tradition and care arrangements in the countries studied (path dependency), and if social innovation and decommodification or (re-)familisation of care effects can be identified. Different social factors favour or restrain the use of professional and informal care resources in family and social networks. Our assumption is that in the Swiss and German socio-political contexts, these factors mean that intermediary structures serve different functions. In both countries, family obligations are important for the care regime but are subject to erosion. In response, Switzerland's intermediary structures seek to support a system of strong professionalism, whereas in Germany, more significant demographic ageing and a lower level of individual wealth has led to a view that professional care cannot be the only, and commonly affordable, answer. Instead, it has led to political claims about strengthening the welfare mix and activating (additional) informal and preventative resources.

In the literature, the Swiss care regime is service-based, with comprehensive professional services and legal entitlements that create choices between, on the one hand, familism with strong professional support, mainly for medical care, and, on the other, final de-familisation, with more reduced family obligations. In contrast, the German care system relies heavily on the family as the LTCI scheme covers professional care to a limited degree and cash-for-care payments favour informal (familial) care (Haberkern and Szydlik, 2008; Saraceno and Keck, 2010). Data on the distribution of informal and professional care in the two countries (see Table 3) show this differentiation: while in Switzerland, formal and informal support are almost on a par with each other (accounting for $47 \%$ and $53 \%$ of people with care needs aged 65+), the situation is very different in Germany. Here, less than $20 \%$ of people in need of care receive professional care services, and the higher share of people giving care in an informal context do so at a higher intensity. Only about $2 \%$ of Swiss parents aged 65+ receive care from their children, compared with 5\% of comparable German parents (Haberkern and Szydlik, 2008).

However, in both countries, decreasing family resources have to be substituted. On both sides of Lake Constance and the Rhine, women form the main caregiver 
potential, and opportunity costs are decisive for informal care. Thus, female labour participation should be an indicator for family carer potential. As Table 4 shows, women's employment rates increased between 2005 and 2015, and slightly more strongly in the German case. Women's higher part-time employment rates seem to compensate for stronger overall participation in Switzerland. As Haberkern et al (2013) report (based on SHARE data ${ }^{7}$ ), family obligation norms are more pronounced in Germany, while in Swiss society, the division of labour (housework, earning money, raising children) is more gendered (traditional). Ultimately, Switzerland and Germany seem to be comparable as regards labour-related conditions of caring; in both countries, general and female employment are increasing and the conditions for family caring are worsening. This will have considerable consequences for the societal costs of care since the availability of informal care in the home environment has a significant impact on the length of stay in residential care homes (Weaver and Weaver, 2014).

In this context, intermediary structures seem to have the potential to support existing care arrangements in different ways. In service-oriented Switzerland, intermediary day and night care structures are quite strongly tied to institutional (inpatient) care facilities, and their function or role can be interpreted as a 'gateway' through which people can enter the professional system. This may be because of the greater wealth of the Swiss compared with Germans (measured by gross domestic product [GDP] in real purchasing power; see Table 4). It seems that Swiss relatives and society are better able to pay the price of formal care (whether additional to informal care or exclusively). In contrast, German intermediary structures are designed to support the informal sphere of caring and support since economic resources are constrained and public perceptions are affected by more rapid population ageing than seen in Switzerland (21.3\% of the population is aged 65+, compared with $17.6 \%$ in Switzerland).

Cultural factors complement this picture. In Switzerland, 22.9\% of people think that the state is responsible for care, while this is true for only $14.3 \%$ in Germany (Haberkern and Szydlik, 2008), while only 10\% of people think that the national LTCI scheme provides adequate coverage (IfD Allensbach, 2009). We can interpret these figures in light of the knowledge that LTC is treated similarly to general health care in Switzerland, whereas considerable extra payments are required in Germany (and that German LTC has been criticised for numerous scandals in recent years). Germans seem resigned to the fact that informal (familial) care is key, and professional services - whether paid for publicly or privately - can only (poorly) supplement 
what (family) carers provide. Among Swiss people, by contrast, there is less doubt about the appropriateness of a service-based system paid for by the state and out-ofpocket expenses. Market-based solutions have a difficult status in the German welfare architecture, and eldercare in particular (eg as seen in the low share of people taking out private supplementary insurance against care risks). Further, Swiss people may be more 'statist' prima facie (at least on the basis of the figures presented here) but have fewer reservations about private-professional solutions. The culture and welfare literature shows that Swiss people avoid holding the state responsible for familyrelated social risks and accept market solutions (Pfau-Effinger, 2008b). A further explanation may be that the strong discourse on the welfare mix, co-production 


\section{7}

and the role of civil society in Germany has promoted non-professional solutions to care (Kehl, 2016a, 2016b).

Intermediary structures in both countries aim to support self-help and selforganising, the reconciliation of work and family life, and welfare choice, but they may serve different functions in the LTC architecture and thus lead to different results. In Switzerland, they add to a fragmented, federalist system and seem to accentuate regional inequalities in care provision. Switzerland has a more medicalised understanding of LTC as only the financing of professional medical care - not social care - is guaranteed through national health insurance. In contrast, the German system has a stronger emphasis on universal LTC provision in the social sector and is more homogeneous due to the integration of intermediary structures in the LTCI scheme. The German system begs the question, however, of whether it can contribute to a more balanced division of labour with its cash-for-care system, which favours traditional care arrangements, and its lack of care leave with earnings replacement. As for the social innovation provided by intermediary structures, the story here is more complex. Intermediary structures are definitely new services and processes responding to changed social demand. In filling the gaps and structural shortcomings of social modernisation, they suggest that the state's role in LTC is a more moderating, facilitating and safeguarding one. They aim to enable people to take responsibility for themselves and their relatives, despite active labour force participation. This is especially true in Germany, where a legal entitlement to such services applies, usage rates have increased significantly and intermediary structures more closely fit the social investment debate. Here, they aim to support carers in and outside the family and to encourage self-help, self-organisation and co-production; whereas in Switzerland, they function more as a 'gateway' to the professional system - and the social investment theme appears rather vague. The German model nevertheless seems to be 'ahead' since short-term and day and night care services were introduced in the 1990s, complemented in recent years by local support centres (and the first care leave opportunities), whereas in Switzerland, these intermediary developments have only just begun. It may be useful, however, to investigate in more detail whether or not the context for LTC policies may give the Swiss public sector a more prominent and investment-oriented role in future.

Finally, intermediary structures do not necessarily shift care responsibilities and disrupt path dependency in LTC provision and the overall welfare architecture. Given the policy environment and economic conditions in the two countries, it is more likely that intermediary structures help stabilise existing patterns of care. In Switzerland, this is consistent with dominant discourses, in which the reconciliation of work and family life played no significant role for a long time, and that are more about sustaining a service-oriented and medicalised approach to professional care. In Germany, a gap can be observed between the 'reconciliation motive' in public discussions and expert claims for mixed welfare, on the one hand, and incentives for family care, on the other. To leverage the full potential of intermediary structures in fine-tuning the welfare mix, they may need to be embedded in a policy setting with effective opportunities for choice. 


\section{Conclusion}

In Switzerland and Germany, intermediary services, such as day and night care, temporary (short-term) stays in nursing homes, respite care, and local infrastructure, complement residential care, home care and family care. Our aim was to address how intermediary structures are located within current LTC models in two 'conservative' welfare regimes, to assess if differences in access and use can be identified, and to consider if they are consistent with welfare traditions and conventional care arrangements. Our analysis substantiates the view that Swiss and German intermediary structures differ in many ways. There is a similar perception of the need for new approaches between both inpatient and outpatient care such as formal (professional) and informal (familial) care, but - despite their similar terminology - they have different functions in the institutional framework, lead to different findings about access and use, and differ concerning path departure.

In Germany, day and night care structures are part of the LTCI scheme at the national level and local support infrastructure exists nationwide, but the Swiss federalist landscape is much more fragmented, with different outcomes for older people and their relatives. Our investigation of access and use reflects these findings, showing that German intermediary structures are generally increasing, while in Switzerland, access and usage rates depend on regional circumstances, where they support stateand market-based professional solutions and are promoted to allow frail older people to live in their homes as long as possible. This seems to strengthen professional care, on the one hand, and to manifest traditional care regimes, on the other.

The German story is somewhat different. In combination with care leave models promoting the reconciliation of work and family life, intermediary structures are part of a lively discussion about the future of LTC and aim to complement the welfare mix. This strategy seeks to 'privatise' care obligations by broadening the informal resource base, at the same time as assigning the state a key role in moderating, facilitating and safeguarding care. It is thus in line with the social investment idea of encouraging individual self-help and co-production. Our analysis, however, questions whether this approach can contribute to a more balanced division of both labour and care duties since a gap between a discursive 'reconciliation theme' and continuing strong incentives for family care persists. In contrast, Swiss intermediary structures function as a 'gateway' to the professional system and lack a comparable discursive substratum, which is why the explanatory power of the social investment approach currently appears rather limited.

With this, intermediary structures refer to the prevailing welfare traditions and cultures of a strong professionalism in Switzerland and family-based care in Germany. Thus, they are drivers of a largely path-dependent policy development with incremental change that is generally in line with the social investment idea of supporting opportunities for choice. In Switzerland, more research is needed to determine if institutional, socio-economic and cultural drivers of LTC policy allow for a more pronounced investment approach. More evidence is also needed on whether the current offer of intermediary structures meets demand and the requirements of frail older people and their relatives, and what can be learned from experiences in other policy areas, such as childcare and care for people with disabilities. 


\section{Notes}

1. The term is a translation of the German 'Intermediäre Strukturen', commonly used in Swiss political debate. It is not the same as the sociological concept 'intermediary institutions', which refers to mediating and collectivising forms of action in churches and civil society organisations building bridges between the individual and society (Berger and Luckmann, 1966).

2. 'Carer' is used throughout for people providing unpaid (sometimes 'informal') care to family members, friends or neighbours, in line with contemporary UK English usage (see International Journal of Care and Caring, 1(1):9).

3. We refer to the 'conservative' welfare regime (Esping-Andersen, 1990), which is addressed in more detail in the second section. Our main point of reference is the dominant role of the family in welfare production - in contrast to the market in the 'liberal' regime and the state in the 'social-democratic' regime. This is why we prefer the label 'conservative' to the rival term 'corporatist'. The latter addresses very similar features but focuses more on how the welfare state is constantly being shaped by corporatist politics, that is, the cooperative modes of bargaining between powerful societal actors and interests, whereas we emphasise policies in the first place (without ignoring the crucial role of social policymaking).

4. The total costs for care during the lifespan (ie the 'care biography', starting with the approval of the medical review board until death) vary remarkably between and within home and residential care. The 50:50 ratio holds as a 'rule of thumb' irrespective of age, sex and care arrangements. Men and people in outpatient care settings make fewer copayments, but, on average, both the LTCI scheme and clients have to pay $€ 40,000$ each (women) or $€ 20,000$ (men) (Rothgang et al, 2012).

5. In both Switzerland and Germany, LTC is characterised by low wages, care migration and a shadow economy. Generally, caregiving is paid better in Switzerland, however (whether in the case of professionals or the informal sector), which is why many certified nurses cross the border for work, accentuating the lack of skilled (professional) caregivers in Germany.

6. Data on access to and use of day and night care structures is still very limited and urgently needs to be enhanced by ongoing investigation. Only 15 of 26 cantons could provide data for the analysis of the study mentioned. Unfortunately, in the Italian-speaking part of Switzerland - the canton of Tessin - no data on day and night care structures were available (Werner et al, 2016).

7. The Survey of Health, Ageing and Retirement in Europe (SHARE) is a cross-national panel survey on health, socio-economic status and social/family networks covering most European countries.

\section{References}

Berger, P.L. and Luckmann, T. (1966) The social construction of reality. A treatise in the sociology of knowledge, London: Penguin Books.

Bischofberger, I., Jähnke, A., Rudin, M. and Stutz, H. (2014) Care allowances and respite care services for caring relatives [Betreuungszulagen und Entlastungsangebote für betreuende und pflegende Angehörige], Schweizweite Bestandesaufnahme, Im Auftrag des Bundesamtes für Gesundheit BAG, Zürich/Bern. 


\section{0}

BMG (Bundesministerium für Gesundheit) (2017) Overview of entitlements to longterm care insurance in 2017 [Leistungsansprüche der Versicherten im Jahr 2017 an die Pflegeversicherung im Überblick], Berlin: Bundesministerium für Gesundheit, https:// www.bundesgesundheitsministerium.de/fileadmin/Dateien/3_Downloads/

Statistiken/Pflegeversicherung/Leistungen/Leistungsbetraege_2017.pdf

Bonoli, G. (2005) The politics of the new social policies: providing coverage against new social risks in mature welfare states, Policy \& Politics, 33(3): 431-49.

Bundesrat (2014) Support for caring relatives. Status quo and need for action in Switzerland: report of the Federal Council [Unterstützung von betreuenden und pflegenden Angehörigen. Situationsanalyse und Handlungsbedarf für die Schweiz. Bericht des Bundesrates], Bern.

Da Roit, B. and Le Bihan, B. (2010) Similar and yet so different: cash-for-care in six European countries' long-term care policies, The Milbank Quarterly, 88(3): 286-309. Esping-Andersen, G. (1990) The three worlds of welfare capitalism, Cambridge: Polity Press.

Esping-Andersen, G. (2002) Why we need a new welfare state, Oxford and New York, NY: Oxford University Press.

Giddens, A. (1994) Beyond Left and Right: The future of radical politics, Cambridge: Polity Press.

Haberkern, K. and Szydlik, M. (2008) Caring parents: a European comparison (Pflege der Eltern: Ein europäischer Vergleich), Kölner Zeitschrift für Soziologie und Sozialpsychologie, 60(1): 82-105.

Haberkern, K., Schmid, T. and Szydlik, M. (2013) Gender differences in intergenerational care in European welfare states, Ageing \& Society, 35(2): 298-320. Heinze, R.G. (2017) Housing and living environments. The center of life in old age [Wohnen und Wohnumfeld. Der Lebensmittelpunkt im Alter], in Generali Zukunftsfonds (ed) Generali Altersstudie 2017. Wie ältere Menschen in Deutschland denken und leben (1st edn), Wiesbaden: SpringerVS, pp 213-29.

Hemereijck, A. (2013) Changing welfare states, Oxford: Oxford University Press. IfD Allensbach (2009) Care in Germany: the population's view on the quality and situation of care - results of a representative survey on behalf of Marseille-Kliniken AG [Pflege in Deutschland: Ansichten der Bevölkerung über Pflegequalität und Pflegesituation - Ergebnisse einer Repräsentativbefragung im Auftrag der Marseille-Kliniken AG], Allensbach: Institut für Demoskopie.

Jenson, J. (2012) Redesigning citizenship regimes after neoliberalism: moving towards social investment, in N. Morel, B. Palier and J. Palme (eds) Towards a social investment welfare state? Ideas, policies and challenges (1st edn), Bristol: Policy Press, pp 61-87. Kazepov, Y. (2010) Rescaling social policies towards multilevel governance in Europe: some reflections on processes at stake and actors involved, in Y. Kazepov (ed) Rescaling social policies: Towards multilevel governance in Europe (1st edn), Farham and Burlington: Ashgate, pp 35-75.

Kazepov, Y. and Ranci, C. (2017) Is every country fit for social investment? Italy as an adverse case, Journal of European Social Policy, 27(1): 90-104.

Kehl, K. (2016a) After the Care Improvement Act II: an alternative interpretation of the problems and a plea for reforms [Nach dem Pflegestärkungsgesetz II: Eine alternative Interpretation der Probleme und ein Plädoyer für potenzialorientierte Reformen], Zeitschrift für Sozialreform, 62(1): 49-78. 


\section{1}

Kehl, K. (2016b) Social investment care policies in Germany: The potential of families and civil society outside the welfare state [Sozialinvestive Pflegepolitik in Deutschland: Familiäre und zivilgesellschaftliche Potenziale im Abseits wohlfahrtsstaatlichen Handelns], Wiesbaden: Springer VS.

Kehl, K. and Stahlschmidt, S. (2016) The limits of monetizing and paying for volunteering in eldercare: a behavioral-economic approach, VOLUNTAS:

International Journal of Voluntary and Nonprofit Organizations, 27(2): 768-89.

Knöpfel, C. (2015) Social policy conditions of the Swiss welfare state [Sozialstaatliche Rahmenbedingungen in der Schwei], in B. Wüthrich, J. Amstutz and A. Fritze (eds) Soziale Versorgung zukunftsfähig gestalten, Wiesbaden: SpringerVS, pp 23-35. Köppel, R. (2015) Successful practices in day care structures [Erfolgreiche Praktiken von Tagesstätten], Rikon: orgavisit.

Krlev, G., Bund, E. and Mildenberger, G. (2014) Measuring what matters: indicators of social innovativeness on the national level, Information Systems Management, 31(3): 200-24.

Obinger, H. and Wagschal, U. (eds) (2000) The controlled welfare state. Social policy in rich industrialised countries [Der gezügelte Wohlfahrtstaat. Sozialpolitik in reichen Industrienationen] (1st edn), Frankfurt and New York, NY: Campus.

Perrig-Chiello, P., Höpflinger, F. and Schnegg, B. (2010) Caring relatives of the elderly in Switzerland [Pflegende Angehörige von älteren Menschen in der Schweiz], https://www.spitex.ch/files/CEAAGB6/SwissAgeCare-2010---Schlussberich Pfau-Effinger, B. (2008a) Erosion of the boundaries between formal and informal work in Europe, keynote speech, International conference 'Transforming Care', SFI Copenhagen, 26-28 July, http://www.sfi.dk Pfau-Effinger, B. (2008b) Cultural change and path departure: the example of family policies in conservative welfare states, in W. van Oorschot, M. Opielka and B. PfauEffinger (eds) Culture and welfare state: Values and social policy in comparative perspective (1st edn), Cheltenham and Northampton, MA: Edward Elgar, pp 185-204.

Razavi, S. (2007) The political and social economy of care in a development context: conceptual issues, research questions and policy options, UNRISD, http://www. unrisd.org

Rodrigues, R. and Nies, H. (2013) Making sense of differences: the mixed economy of funding and delivering long-term care, in K. Leichsenring, J. Billings and $\mathrm{H}$.

Nies (eds) Long-term care in Europe (1st edn), Basingstoke and New York, NY: Ashgate, pp 191-212.

Roth, D.L., Perkins, M., Wadley, V.G., Temple, E.M. and Haley, W.E. (2009) Family caregiving and emotional strain: associations with quality of life in a large national sample of middle-aged and older adults, Quality of Life Research, 18(6): 679-88. Rothgang, H., Müller, R., Unger, R., Weiß, C. and Wolter, A. (2012) BARMER GEK care report 2012 - spotlight on costs in case of care [BARMER GEK Pflegereport 2012 - Schwerpunktthema: Kosten bei Pflegebedürftigkeit], Siegburg: BARMER GEK Saraceno, C. (2008) Delivering and receiving care. Between individualisation and re-familialisation [Care leisten und Care erhalten. Zwischen Individualisierung und Refamilialisierung], Berliner Journal für Soziologie, 2: 244-56.

Saraceno, C. and Keck, W. (2010) Can we identify intergenerational policy regimes in Europe?, European Societies, 12(5): 675-96.

Schneider, U. (2006) Informal care from an economic perspective [Informelle Pflege aus ökonomischer Sicht], Zeitschrift für Sozialreform, 52(4): 493-520. 


\section{2}

Statistisches Bundesamt (2017) Care in the long-term care insurance: comparison of countries - persons in need [Pflege im Rahmen der Pflegeversicherung: Ländervergleich Pflegebedürftige], Wiesbaden: Statistisches Bundesamt.

Strohmeier Navarro Smith, R. (2010) Familiarisation and regional variation in longterm care provision: a comparative perspective on long-term care for older people

in Europe, in Y. Kazepov (ed) Rescaling social policies: Towards multilevel governance in Europe (1st edn), Farham and Burlington: Ashgate, pp 277-312.

Strohmeier Navarro Smith, R. (2012) Long-term care in Switzerland. A federal policy

domain in European comparison [Alterspflege in der Schweiz. Ein föderal geprägtes Politikfeld im europäischen Vergleich], Bern: Peter Lang.

Ungerson, C. and Yeandle, S. (2007) Cash for care in developed welfare states, New York, NY: Palgrave Macmillan.

Walker, A.J., Pratt, C.C. and Eddy, L. (1995) Informal caregiving to aging family members: a critical review, Family Relations, 44(4): 402-11.

Weaver, F.M. and Weaver, B.A. (2014) Does availability of informal care within the household impact hospitalisation?, Health Economics, Policy and Law, 9(1): 71-93.

Werner, S., Kraft, E., Mohagheghi, R., Meuli, N. and Egli, F. (2016) Supply and use of intermediary structures for the elderly in Switzerland. Results from an enquiry of the cantons and analyses of the statistics of social-medical institutions [Angebot und Inanspruchnahme von intermediären Strukturen für ältere Menschen in der Schweiz. Ergebnisse einer Kantonsbefragung und einer Auswertung der Statistik der sozialmedizinischen Institutionen], Obsan Dossier 52, Neuchâtel. 
Table 1

Landscape and features of intermediary structures in Switzerland and Germany

\begin{tabular}{|l|l|l|l|l|r|}
\hline & $\begin{array}{l}\text { Inpatient } \\
\text { (residential) } \\
\text { care }\end{array}$ & $\begin{array}{l}\text { Respitelshort- } \\
\text { term care }\end{array}$ & $\begin{array}{l}\text { Day and } \\
\text { night care }\end{array}$ & $\begin{array}{l}\text { Outpatient } \\
\text { (ambulant) } \\
\text { care }\end{array}$ & $\begin{array}{l}\text { Infrastructures } \\
\text { for informal } \\
\text { assistance }\end{array}$ \\
\hline Formality & \multicolumn{3}{|l|}{ Formal (professional staff) } & \multicolumn{2}{|l|}{ Informal (laymen) } \\
\hline Care needs & High & \multicolumn{1}{|c|}{ Medium } & Low \\
\hline $\begin{array}{l}\text { Governance } \\
\text { \& Financing }\end{array}$ & \multicolumn{3}{|l|}{$\begin{array}{l}\text { National (social insurance schemes) and regional (Switzerland: cantonal and local } \\
\text { care models; Germany: state implementation) }\end{array}$} \\
\hline
\end{tabular}

\section{Table 2}

Access and use of intermediary structures compared

\begin{tabular}{|l|l|l|}
\hline Access & Switzerland & Germany \\
\hline Use & $\begin{array}{l}\text { Limited through financing } \\
\text { schemes (only coverage of } \\
\text { health-related care cost } \\
\text { through the health insurance is } \\
\text { nationally regulated) }\end{array}$ & $\begin{array}{l}\text { Day and night care: Universal } \\
\text { access, national law (LTC } \\
\text { insurance) and nationwide } \\
\text { quasi-market with major } \\
\text { service providers; local support } \\
\text { centres depend on } \\
\text { state/municipality legislation }\end{array}$ \\
\hline & $\begin{array}{l}\text { Limited } \\
\text { High regional variation (partly } \\
\text { cantons without intermediary } \\
\text { structures at all) }\end{array}$ & $\begin{array}{l}\text { Increased substantially } \\
\text { Day and night care (LTC } \\
\text { insurance): Low regional } \\
\text { variation; local support centres: } \\
\text { high regional variation }\end{array}$ \\
\hline
\end{tabular}

\section{Table 3}

\section{Distribution of formal (professional) and informal care}

\begin{tabular}{|l|c|c|}
\hline & Switzerland & Germany \\
\hline $\begin{array}{l}\text { Total formal (professional) care } \\
\text { (\% of people aged 65 and over } \\
\text { with care needs) }\end{array}$ & 47 & 17.8 \\
\hline Inpatient (in residential homes) & 15.8 & 11.8 \\
\hline Outpatient (at home) & 31.1 & 82.2 \\
\hline $\begin{array}{l}\text { Total informal care (\% of } \\
\text { people aged 65 and over with } \\
\text { care needs) }\end{array}$ & 53 & 6.9 \\
\hline $\begin{array}{l}\text { Intensity of informal care } \\
\text { provided (median weekly } \\
\text { hours) }\end{array}$ & 5.7 & \\
\hline
\end{tabular}




\section{Relevant social indicators}

\begin{tabular}{|c|c|c|c|c|c|c|}
\hline & \multicolumn{3}{|c|}{ Switzerland } & \multicolumn{3}{|c|}{ Germany } \\
\hline & 2005 & 2015 & & 2005 & 2015 & \\
\hline $\begin{array}{l}\text { Total employment rate (\% of } \\
\text { working age population) }\end{array}$ & 77.2 & 80.2 & $+3.9 \%$ & 65.5 & 74.0 & $+13.0 \%$ \\
\hline $\begin{array}{l}\text { Women's employment rate (\% } \\
\text { of working age population) }\end{array}$ & 70.4 & 76.0 & $+8.0 \%$ & 59.6 & 69.9 & $+17.3 \%$ \\
\hline $\begin{array}{l}\text { Total part-time employment } \\
\text { rate (\% of employment) }\end{array}$ & 25.1 & 26.8 & $+6.8 \%$ & 21.5 & 22.4 & $+4.2 \%$ \\
\hline $\begin{array}{l}\text { Women's part-time } \\
\text { employment rate (\% of } \\
\text { employment) }\end{array}$ & 45.7 & 45.0 & $-1.6 \%$ & 38.8 & 37.4 & $-3.7 \%$ \\
\hline $\begin{array}{l}\text { GDP per capita, current prices } \\
\text { (USD) }\end{array}$ & $54,959.24$ & $80,602.69$ & $+46.7 \%$ & $34,769.26$ & $40,952.42$ & $+17.8 \%$ \\
\hline $\begin{array}{l}\text { GDP based on PPP per capita } \\
\text { (CID) }\end{array}$ & $45,313.06$ & $58,647.20$ & $+29.4 \%$ & $34,020.45$ & $46,973.92$ & $+38.1 \%$ \\
\hline $\begin{array}{l}\text { Working age population (\% of } \\
\text { people aged } 15 \text { to } 64 \text { ) }\end{array}$ & 68.0 & $67.5^{\star}$ & $-0.7 \%$ & 66.9 & 65.6 & $-2.0 \%$ \\
\hline $\begin{array}{l}\text { Elderly population (\% of } \\
\text { people aged } 65 \text { and over) }\end{array}$ & 15.9 & $17.6^{*}$ & $+10.7 \%$ & 19.2 & $21.3^{*}$ & $+10.9 \%$ \\
\hline $\begin{array}{l}\text { Total fertility rate } \\
\text { (children/woman) }\end{array}$ & 1.4 & 1.5 & $+7.1 \%$ & 1.3 & 1.5 & +15.4 \\
\hline
\end{tabular}

Sources: OECD, IMF (PPP = purchasing-power-parity; GDP = gross domestic product; USD = US dollars; CID = current international dollars; * $=2013$ data) 